\title{
Electric inductance probe application of corrosion monitoring in the
}

\section{backfill environment}

\author{
Lou miao, Huang yingjun, Lu yufeng, Zhou meng, Li shasha \\ Northwest Institute of Nuclear Technology, Xi'an 710024, China
}

Key words: electric inductance probe; backfill environment; corrosion monitoring

\begin{abstract}
A entirely corrosion monitoring technology-electric inductance probe sensor technology was introduced in this paper. Its operating principle and probe structure were summarized. Study on the corrosion monitoring technology of the electric inductance probe in betons and bentonites environment. The results showed that the corrosion monitoring effect of electric inductance probe are nice. It is believed that the inductance probe is an effectively means of the corrosion monitoring technology of entirely corrosion. It can supply the technology assist of sealed containers of radioactive waste for long-term safe management.
\end{abstract}

In a project, part of the $16 \mathrm{MnR}$ steel sealed containers that seal radioactive wastes are backfilled, which are backfilled in the environment of lightweight aggregate concrete and bentonite. To achieve its long-term security management, prevent the occurrence of environmental pollution, it is necessary to carry out corrosion monitoring, to obtain the information that the corrosion of container material in landfill environment changes with the time, which can provide data support for their life prediction and performance evaluation, but at present, the reports on corrosion monitoring about lightweight aggregate concrete and bentonite in this special landfill environment at home and abroad are less ${ }^{[1-4]}$. Therefore, an inductance probe sensor is designed to meet the actual needs, the paper describes the design principles and specific applications of inductance probe sensor, and through its practical application in landfill environment of concrete and bentonite, the using effect is evaluated.

\section{Working principles and structure of inductance probe sensor}

\section{Working principles}

Inductance probe is an effective way of indirectly monitoring device corrosion, it regards metal corrosion loss as the foundation, and it calculates corrosion loss speed by measuring the AC signal change caused by corrosion thin zone of corrosion spool. For the measuring element inserted in pipelines, and its measuring element decreases after the corrosion, which will cause the change of AC signal, to impose AC signal to measurement test block, and thickness reduction and thickness reduction of measuring element are calculated by the change of AC signal. When texture of measuring element, washing state of measuring element and other objective conditions are substantially the same as the state of the measured devices, the corrosion rate of the devices can be approximatively represented by corrosion rate of measuring element, compared with corrosion hanging slice method, electrical resistance probe acoustic emission method and other monitoring methods, inductance probe has the features of the continuous monitoring, the short response time, the wide range of application ${ }^{[5-7]}$.

\section{Structure of sensor}

Inductance probe sensors are mainly made of siphonate test blocks that have the same texture 
as the metal devices and solenoid coil in test blocks, as shown in Figure 1. The texture of siphonate inductance probe is $16 \mathrm{MnR}$ stainless steel material, the textures of other parts are $20 \#$ steel tube with the thickness of $2 \mathrm{~mm}$, and the glue is poured into the pipe, connecting lines in the pipes are respectively used for galvanization, temperature compensation and measurement. Different thickness and texture of metal coupon have different effects on magnetic field intensity of solenoid coil, and the brought inductance value of coil is different, so when the metal coupon has corrosion thin zone, it will influence equivalent inductance and inductive reactance of test coil, we can calculate the amount of corrosion thin zone of metal coupon by detecting inductance variable quantity.

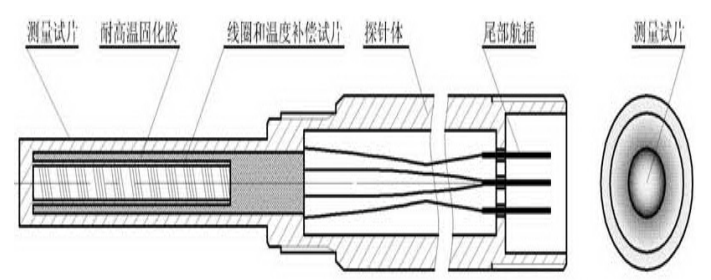

Fig.1 Structure of the electric inductance probe

\section{Application of inductance probe in the landfill environment}

For the sealed container, corrosion control methods and measures are adopted, in surface of partial inductance probe sensor, anti-corrosion coatings are prepared, inductance probe sensors with and without coatings are respectively backfilled in lightweight aggregate concrete and bentonite environments, as shown in Figure 2, using DG9680 inductance probe erosion monitoring system of Metal Station of Chinese Academy of Sciences to monitor the time-dependent information of their corrosion.
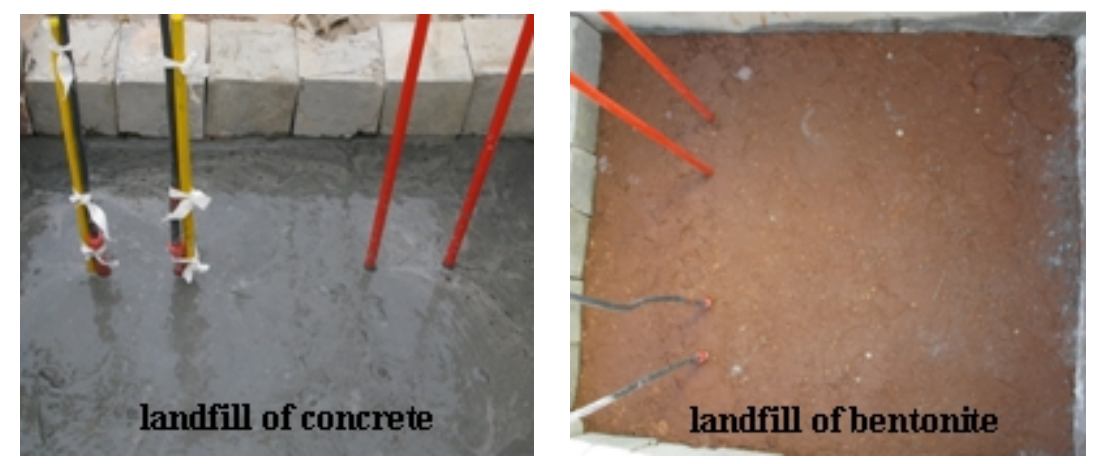

Fig.2 Backfill process of the electric inductance probe

\section{Application in Concrete}

In the lightweight aggregate concrete backfill environment, continuous monitoring results are shown in Figure 3, the changes of corrosion losses of 1 \#, 3 \# probe are little, and equivalent to initial zero point value of probe, all of the corrosion rate are $0 \mathrm{~mm} / \mathrm{a}$, in which the corrosion losses of the probe with coating are more stable. On the one hand, the monitoring results explain that the protective effect of coating in lightweight aggregate concrete environment is better, the probe with coating is not corroded; on the other hand, the monitoring results explain that lightweight aggregate concrete has weak corrosion for $16 \mathrm{MnR}$ steel, the $\mathrm{PH}$ value is between $12 \sim 14$, the highly alkaline environment makes a weaker corrosiveness of the environment, $16 \mathrm{MnR}$ bare steel does not have corrosion. 




Fig. 3 Corrosion wasting of the electric inductance probe in betons

\section{Application in bentonite}

In the bentonite backfill environment, continuous monitoring results are shown in Figure 4, the changes of corrosion losses of 2 \# probe with coating are little, the corrosion rate is $0 \mathrm{~mm} / \mathrm{a}$, which also shows that the coating in bentonite environment has better protecting effects, and the probe with coating does not have corrosion. The corrosion rate of 4 \# probe without coating is $0.02 \mathrm{~mm} / \mathrm{a}$, which shows that $16 \mathrm{MnR}$ bare steel has corrosion in bentonite environment, because water blending and stirring are done for bentonite before the rolled backfill, and it moisture content reaches about $26 \%$, in order to achieve a better shielding block effect, so moisture content of back-filling layer of initial bentonite near the surface of the probe has a slight corrosion.

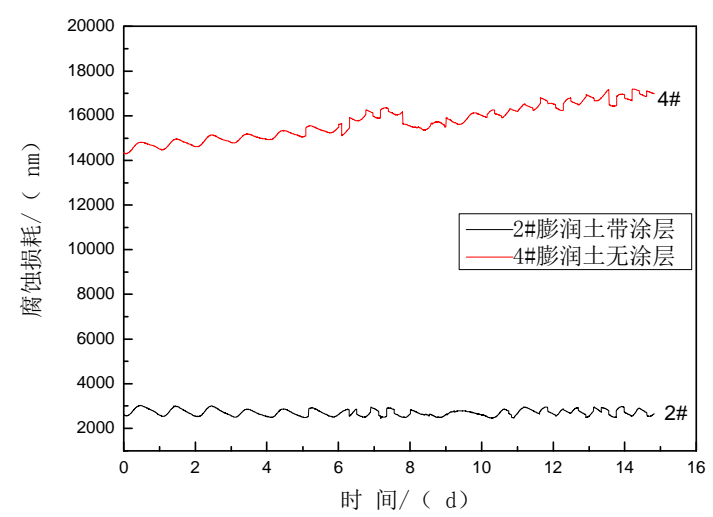

Fig.4 Corrosion wasting of the electric inductance probe in bentonites

The corrosion monitoring data of concrete and bentonite in the backfill environment are obtained by the continuous monitoring of inductive probe in the landfill environment. The subsequent data in long-term measurement for different backfill materials by inductance probe sensor are shown in Figure 5, the corrosion losses of 3\# concrete probe without coating are little, and equivalent to the initial zero value of probe, the corrosion rate is $0 \mathrm{~mm} / \mathrm{a}$; the corrosion rate of 4 \# uncoated probe of bentonite is $0.02 \mathrm{~mm} / \mathrm{a}$. This is identical to corrosion data monitored by inductance probe in the initial stage of backfill, the corrosion rate in lightweight aggregate concrete environment is $0 \mathrm{~mm} / \mathrm{a}$, the corrosion rate in bentonite environment is $0 \sim 0.02 \mathrm{~mm} / \mathrm{a}$. Monitoring results show that the corrosion monitoring results are better, quantitative measurement of the corrosion rate, is an effective uniform corrosion monitoring method. 




Fig.5 Corrosion wasting of the electric inductance probe

\section{Conclusion}

(1) Inductance probe sensor are applied in two backfill environment: lightweight aggregate concrete and bentonite, and the corrosion-monitoring data after landfill treatment are obtained, which verify the technical feasibility of simulating on-line monitoring of this technique used in special landfill state;

(2) Inductance probe sensor technology can timely and accurately response to lightweight aggregate concrete and bentonite environment, and quantitatively measure corrosion rate, which is an effective indirect uniform corrosion monitoring method;

(3) Inductance probe sensor technology can do real time on-line monitoring for the changes of corrosion rate in special landfill environment, and provide the technical basis for the long-term safe management of radioactive waste sealed container.

\section{References}

[1] YANG fei, ZHOU yong-feng. Progress of Corrosion and Protection Monitoring/Inspection Technologies [J], Total Corrosion Control,2009,23(11): 50-53.

[2] CHEN Jian-she,YANG Dong. Coupled multielectrode array sensors for localized corrosion monitoring [J], Journal of Materials and Metallurgy,2008,7(3):233-238.

[3] Sun X D, Yang L T. Real-time monitoring of localized and general corrosion rates in king water systems utilizing coupled multielectrode array sensors[C], Corrosion. Houston, TX: NACE International, 2006.

[4] Yang L T, SridharN. Coupled multielectmde array system and sensors for real-time corrosion monitoring A review[C] ,Corrosion Houston , TX: NACE International,2006.

[5] Yang lie tai. Corrosion Monitoring Technology [M]. BeiJing: Chemical Industry press,2012.

[6] Li jiu qing, Du cui wei. Corrosion Test Method and Monitoring Technology [M]. Bei Jing:China Petrochemical Press ,2007.

[7] ZHANG Ju-sheng, DU Yue-xia. Corrosion Monitoring and Reasonable Selection[J], Corrosion \& Protection,2012,22(3):75-78. 